\title{
Investigation on Growth, Structural, Spectral, Optical, and Mechanical Properties of an Organic Nonlinear Optical Material: Morpholinium Hydrogen Tartrate
}

\author{
R. Renugadevi ${ }^{1}$ and R. Kesavasamy ${ }^{2}$ \\ ${ }^{1}$ Department of Physics, SriGuru Institute of Technology, Coimbatore, Tamilnadu 641 110, India \\ ${ }^{2}$ Department of Physics, Sri Ramakrishna Engineering College, Coimbatore, Tamilnadu 641 020, India \\ Correspondence should be addressed to R. Kesavasamy; kesav_cbe@yahoo.co.in
}

Received 29 September 2013; Revised 18 November 2013; Accepted 22 November 2013; Published 5 January 2014

Academic Editor: Mohindar S. Seehra

Copyright (C) 2014 R. Renugadevi and R. Kesavasamy. This is an open access article distributed under the Creative Commons Attribution License, which permits unrestricted use, distribution, and reproduction in any medium, provided the original work is properly cited.

\begin{abstract}
Organic nonlinear optical crystal morpholinium hydrogen tartrate (MHT), with molecular formula $\left[\mathrm{C}_{8} \mathrm{H}_{15} \mathrm{NO}_{7}\right]$, has been grown by slow evaporation solution technique. Single crystal X-ray diffraction study confirms that MHT crystallizes in orthorhombic system with noncentrosymmetric space group P $2_{1} 2_{1} 2_{1}$. FTIR spectrum was recorded to identify the various functional groups of MHT. The various kinds of protons and carbons of MHT have been identified using ${ }^{1} \mathrm{H}$ and ${ }^{13} \mathrm{C}$ NMR spectral analyses. The range of optical absorption was ascertained by recording UV-Vis-NIR spectral studies. The TG/DTA studies revealed that the grown crystal is thermally stable up to $159.26^{\circ} \mathrm{C}$. The mechanical property of the grown crystal was studied using Vickers microhardness studies. The relative second harmonic generation efficiency of MHT was determined using Kurtz and Perry powder technique; it was observed to be greater than that of KDP crystal.
\end{abstract}

\section{Introduction}

In recent years, organic nonlinear optical crystals have been greatly investigated due to their high nonlinearities and rapid response in electrooptic effect compared to inorganic materials. The organic nonlinear optical crystals provide the key functions of frequency conversion, optical switching, telecommunication, colour display, and second harmonic generation. Within the last few years, much progress has been made in the development of nonlinear optical organic materials for second harmonic generation. However, most of the organic NLO crystals are constituted by weak van der Waals and hydrogen bonds with conjugated $\pi$ electrons [1].

Morpholine is a strong alkali, which can be considered as a kind of secondary aliphatic amine. However, the incorporation of nitrogen into the six-member ring exposes the lone electron pair on nitrogen and makes the molecule as a good nucleophile. Morpholine and its derivatives are known to form a series of molecular complexes such as morpholine [2], hydrohalides [3], phenols [4], and phosphoric acid
[5]. Recently, the structure and various characterizations of nonlinear optical crystal of morpholinium 4-aminobenzoate have been reported [6].

The crystal structure of morpholinium hydrogen tartrate was reported by Liu [7], but there are no reports available on the growth and other characterizations of morpholinium hydrogen tartrate. The crystal complex was formed by the transformation of one proton of the L-tartaric acid to the nitrogen atom of morpholine. In the present investigation, crystal growth, structural, spectral, optical, thermal, and mechanical properties of morpholinium hydrogen tartrate, with molecular formula $\left[\mathrm{C}_{8} \mathrm{H}_{15} \mathrm{NO}_{7}\right]$ have been reported.

\section{Experiment}

2.1. Synthesis and Crystal Growth. Morpholinium hydrogen tartrate single crystals were synthesized from morpholine (Merck GR grade) and L-tartaric acid. The $4.5 \mathrm{~mL}$ of morpholine dissolved in $150 \mathrm{~mL}$ ethanol and $7.504 \mathrm{~g}$ of L-tartaric acid was added to this by continuous stirring. A homogeneous 


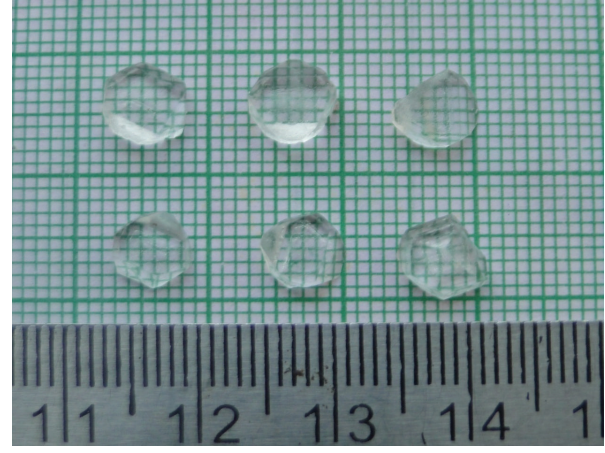

FIGURE 1: As-grown single crystals of MHT.

aqueous solution of morpholinium hydrogen tartrate was prepared by mixing morpholine with saturated solution of Ltartaric acid. The reaction was exothermic and some white fumes were observed; the turbid white solution of the acid turned to yellow on addition of the colorless morpholine and the preparative solution temperature became $45^{\circ} \mathrm{C}$. To make the homogeneous solution, it was continuously stirred well for about 6 hours and then evaporated to dryness. The dried salt was collected for further growth of MHT. The synthesized compound was further improved by successive recrystallization process.

The prepared solution was filtered off using WhatMan filter paper to remove the suspended impurities. The saturated solution covered with perforated cover as well as 10 holes was made for control evaporation. The beaker was kept in a separate cupboard to maintain the undisturbed condition. Single crystals of morpholinium hydrogen tartrate were grown from the supersaturation solution at room temperature. At that time, the temperature was $34^{\circ} \mathrm{C}$. The solution was inspected day and night and after 30 days of growth period, good quality single crystals of MHT have been harvested with maximum size up to $7 \times 8 \times 2 \mathrm{~mm}^{3}$ as shown in Figure 1.

\section{Characterization}

3.1. Single Crystal X-Ray Diffraction Studies. Single crystal $\mathrm{X}$-ray diffraction study was carried out using a Bruker AXS (Kappa Apex II) diffractometer with Mo K $\alpha$ (0.71073 $)$ radiation at room temperature. The estimated cell parameters of MHT crystals are $a=7.24 \AA, b=9.04 \AA, c=16.20 \AA$, and $V=1064 \AA^{3}$. The MHT crystal belongs to orthorhombic system with the space group of $\mathrm{P} 22_{1} 2_{1} 2_{1}$. It is observed that lattice parameter values of MHT are in good agreement with the reported values [7].

3.2. Fourier Transform Infrared Analysis. The FTIR spectrum of the crystal was recorded using $\mathrm{KBr}$ pellet technique in the frequency region of $400-4000 \mathrm{~cm}^{-1}$ using a JASCO FTIR spectrometer. The FT-IR spectrum of MHT is shown in Figure 2. A strong band observed at $3510 \mathrm{~cm}^{-1}$ is assigned to free $\mathrm{OH}$ stretching vibrations. The characteristic absorption peaks at 3419 and $3310 \mathrm{~cm}^{-1}$ are assigned to $\mathrm{NH}_{2}{ }^{+}$asymmetric

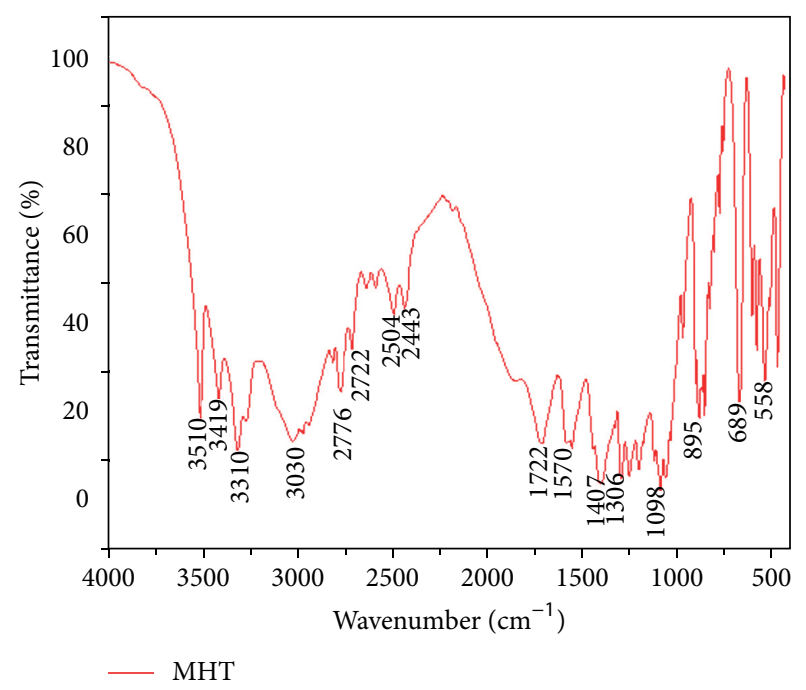

FIGURE 2: FTIR spectrum of MHT.

and symmetric stretching vibrations, respectively. The intense peaks at 3030 and $2990 \mathrm{~cm}^{-1}$ are due to asymmetric and symmetric $\mathrm{CH}$ stretching vibrations. The sharp peaks at 2504 and $2443 \mathrm{~cm}^{-1}$ are due to the overtones and combinations. The $\mathrm{C}=\mathrm{O}$ stretching vibration occurred at $1722 \mathrm{~cm}^{-1}$. The peak at $1570 \mathrm{~cm}^{-1}$ is assigned to the $\mathrm{NH}_{2}$ bending vibration. The symmetric and asymmetric $\mathrm{COO}^{-}$vibrations produced peaks at 1407 and $1563 \mathrm{~cm}^{-1}$, respectively. The absorptions peaks at 1167 and $1098 \mathrm{~cm}^{-1}$ are due to the asymmetric and symmetric stretching vibration of $\mathrm{C}-\mathrm{O}-\mathrm{C}$ group, respectively.

3.3. Nuclear Magnetic Resonance (NMR) Studies. In the present investigation, ${ }^{1} \mathrm{H}$ NMR and ${ }^{13} \mathrm{C}$ NMR spectra of the MHT have been recorded with a JEOL-GSX 4000 NMR spectrometer operating at $400 \mathrm{MHz}$ with $\mathrm{D}_{2} \mathrm{O}$ as a solvent. The ${ }^{1} \mathrm{H}$ and ${ }^{13} \mathrm{C}$ NMR spectrum of MHT is shown in Figure 3 (A, B). In proton NMR, the signal that appears at $\delta=4.2 \mathrm{ppm}$ is due to $\mathrm{CH}$ (a) of tartaric acid (2H, Doublet). The triplet signal at $\delta=3.8 \mathrm{ppm}$ and $\delta=3.2 \mathrm{ppm}$ is assigned to the $\mathrm{CH}_{2}$ (b and c) protons of morpholinium cation. The assignment of each signal to a unique carbon environment molecule is also indicated. The ${ }^{13} \mathrm{C}$ NMR spectrum consists of 4 signals. The signals at $\delta=43.21 \mathrm{ppm}$ and at $\delta=63.58 \mathrm{ppm}$ are assigned for carbons of morpholine, respectively. The presence of signal at $\delta=176.267 \mathrm{ppm}$ is due to the carbonyl carbon of $\mathrm{COOH} / \mathrm{COO}^{-}$of tartaric acid. Similarly, the resonance signal at $\delta=72.751 \mathrm{ppm}$ is attributed to the $\mathrm{CH}$ of tartaric acid.

3.4. Optical Transmission Spectral Studies. The absorption spectrum of MHT was recorded in the wavelength range 200 to $1100 \mathrm{~nm}$ using Perkin Elmer Lambda 35 spectrometer. The spectrum gives information about the structure of molecules, because the absorption of UV and visible light involves promotion of the electron in the $\sigma$ and $\pi$ orbital from the ground state to higher states [8]. The MHT crystal is active 


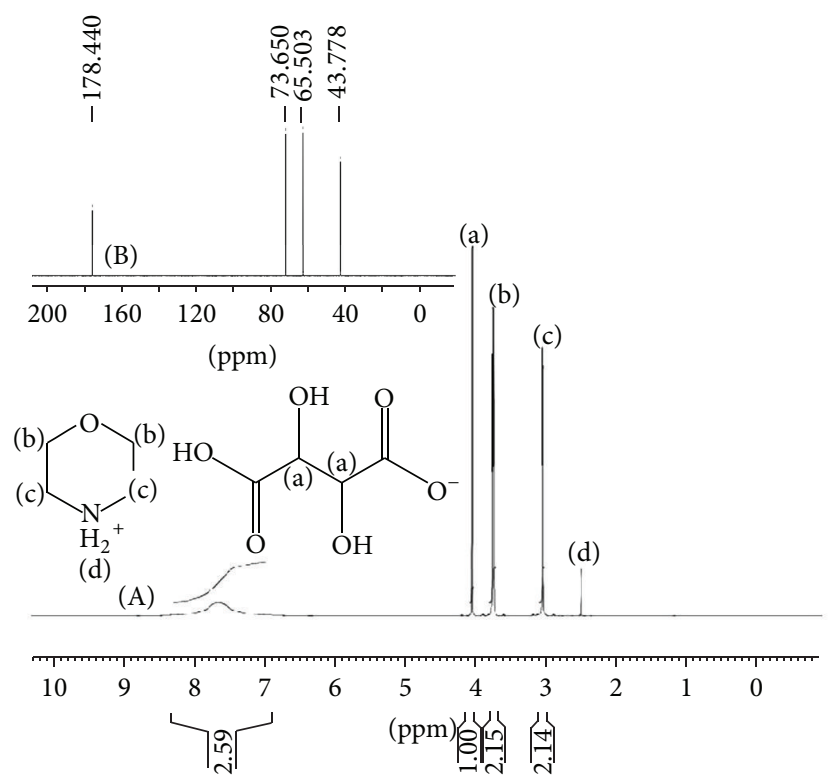

Figure 3: (A) ${ }^{1} \mathrm{H}$ and (B) ${ }^{13} \mathrm{C}$ NMR spectrum of MHT.

in the UV-Vis region and the compound material could be a viable alternative for optical material in the entire visible region. The observed nature of absorption in the visible region is a desirable property for NLO applications. The absorption spectrum of MHT crystal is shown in Figure 4(a). The optical absorption coefficient $(\alpha)$ was calculated using the relation

$$
\alpha=\frac{2.3026(1 / T)}{t}
$$

where $T$ is the transmittance and $t$ is thickness of the crystal.

Optical band gap $\left(E_{g}\right)$ was evaluated from the transmission spectra and optical absorption coefficient $(\alpha)$ near the absorption edge is given by [9]

$$
(\alpha h \nu)^{2}=A\left(h v-E_{g}\right)
$$

where $A$ is a constant, $E_{g}$ is the optical band gap, $h$ is the Planck constant, and $v$ is the frequency of the incident photons. The band gap of MHT crystal was estimated by plotting $(\alpha h v)^{2}$ versus $h v$ as shown in Figure 4(b) and extrapolating the linear portion near the onset of absorption edge to the energy axis. From the figure, the value of band gap was found to be $5.17 \mathrm{eV}$.

3.5. Thermal Studies. Thermal studies were carried out using NETZSCH-Geratebau STA 409 PC thermal analyzer. The experiment was performed in a nitrogen atmosphere. In order to find out the thermal stability and decomposition steps of MHT, $5.86 \mathrm{mg}$ of powdered sample was taken for TG/DTA studies and the corresponding thermograms are shown in Figure 5. The DTA trace indicating endothermic starting at about $170.86^{\circ} \mathrm{C}$ indicates the good degree of crystallinity and melting point of the MHT compound and the second endothermic peak starting at $191.85^{\circ} \mathrm{C}$ is due to the decomposition of the compound. From the TGA trace, it was found that the material is stable up to $159.26^{\circ} \mathrm{C}$ and weight loss occurred drastically up to $239.64^{\circ} \mathrm{C}$ due to the complete decomposition of the material. From the thermal analyzes, the crystal is found to stable up to the temperature $159.26^{\circ} \mathrm{C}$. Hence, the material can be exploited for any suitable application up to $159.26^{\circ} \mathrm{C}$.

3.6. Microhardness Studies. The structure and molecular composition of the crystalline solids are inviolably related to the mechanical hardness. Hardness of the material is a measure of the resistance it offers to local deformation [10]. Microhardness measurement was carried out on asgrown flat face of MHT crystal using Leitz-Wetzler hardness tester fitted with Vickers diamond indenter. Vickers hardness number $H_{v}$ was calculated from the following relation [11]:

$$
H_{v}=1.8544\left(\frac{P}{d^{2}}\right) \mathrm{kg} / \mathrm{mm}^{2}
$$

where $H_{v}$ is the hardness number, $P$ is the applied load, and $d$ is the diagonal length measured in micrometer. The variation of load is ranging from 1 to $100 \mathrm{~g}$. Figure 6 shows the variation of hardness number with load and the plot of $\log (P)$ against $\log (d)$. A hardness number increase with an increase in applied load is called reverse indentation size effect [12]. The crystal is stable up to $100 \mathrm{~g}$. The plot of $\log (P)$ against $\log (d)$ is a straight line shown in Figure 6, which is in good agreement with Meyer's relation $P=k_{1} d^{n}$ [13], where $k_{1}$ is material's constant and " $n$ " is Meyer's index or work hardening coefficient. The slope of the graph gives " $n$ " value and it was found to be 3.1. According to Onitsch theory [14], if $n$ value is less than 1.6, the materials are said to be harder ones. If $n$ value is greater than 1.6, the materials are said to be softer ones. Hence, MHT crystal belongs to soft material category.

3.7. Nonlinear Optical Studies. Morpholinium tartrate is crystallized in noncentrosymmetric crystal system. Nonlinear polarization of morpholinium tartrate is the origin of SHG efficiency. The second harmonic generation (SHG) efficiency has been carried out using Kurtz and Perry powder technique [15]. A Q-switched Nd: YAG laser operating at $1064 \mathrm{~nm}$ radiation with $10 \mathrm{~ns}$ was used. The second harmonic generation was confirmed by the emission of green light. Microcrystalline material of KDP was used as reference material in the second harmonic generation measurement. The relative SHG efficiency of grown crystal was found to be 1.16 times higher than that of KDP crystal.

\section{Conclusion}

A potential second-order nonlinear optical material Morpholinium hydrogen tartrate was grown by slow evaporation technique. Single crystal X-ray diffraction analysis was used to estimate the cell parameters and the compound easily crystallizes in an orthorhombic system with noncentrosymmetric space group $\mathrm{P} 2_{1} 2_{1} 2_{1}$. The spectroscopic 


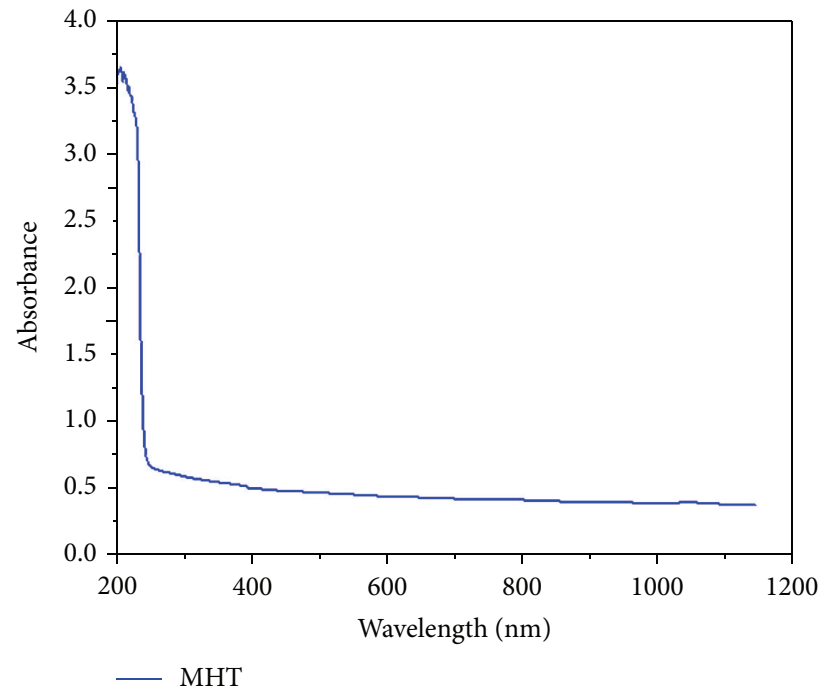

(a)

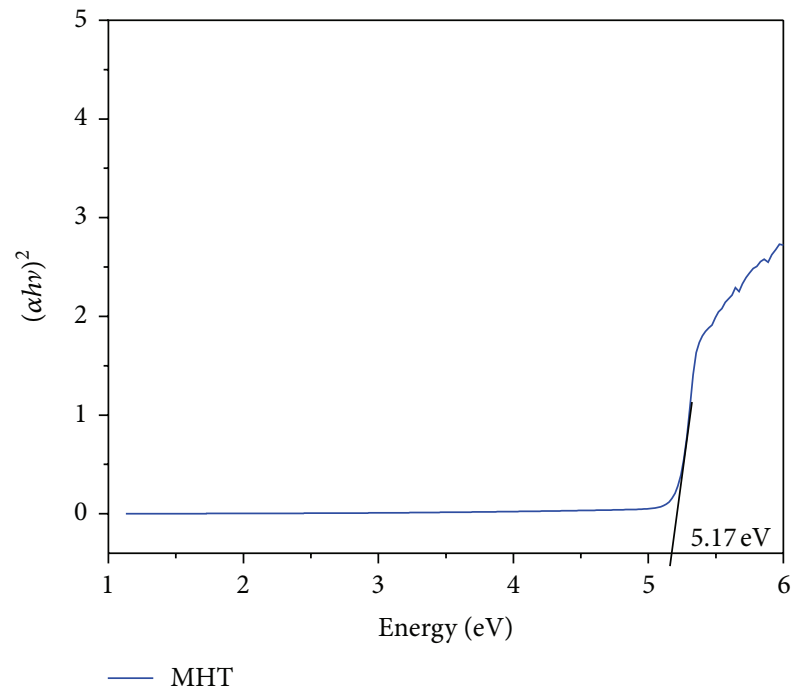

(b)

FIGURE 4: (a) Absorbance spectrum of MHT. (b) Plot of $(\alpha h v)^{2}$ versus photon energy of MHT.

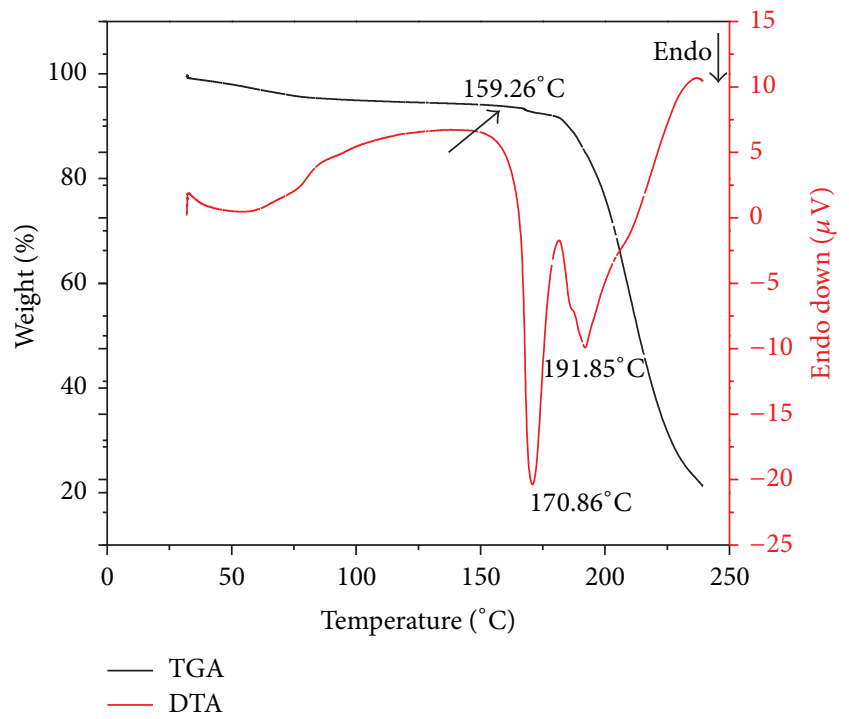

Figure 5: TG/DTA curve of MHT.

analysis confirms the functional groups of the grown morpholinium hydrogen tartrate. The presence of carbons and protons was confirmed by ${ }^{1} \mathrm{H}$ and ${ }^{13} \mathrm{C}$ NMR analyses. The ultraviolet-visible spectral analysis shows that the material does not absorb appreciably in the range of $200-1100 \mathrm{~nm}$, thus confirming the suitability of this material for second harmonic generation applications. From the TGA curve, it is seen that the material is stable up to $159.26^{\circ} \mathrm{C}$. Mechanical properties of MHT crystals were also analyzed. From that, the work hardening coefficient $n$, a measure of the strength of the crystal, was calculated and it is found to be 3.1, which confirmed that the crystal belongs to moderately soft material category. The second harmonic generation relative efficiency

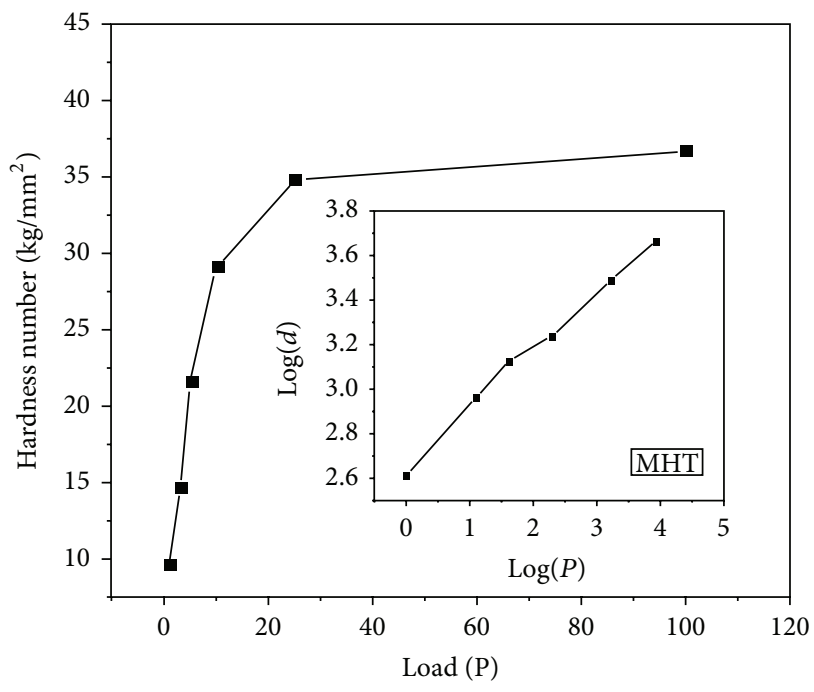

FIgURE 6: Variation of microhardness number with load and $\log (P)$ versus $\log (d)$.

of MHT was found to be 1.16 times higher than that of KDP crystal.

\section{Conflict of Interests}

The authors declare that there is no conflict of interests regarding the publication of this paper.

\section{Acknowledgments}

The authors thank the Management, Principal, and Head of the Department of Science and Humanities, SriGuru Institute of Technology, Coimbatore, for their encouragement and everlasting support. The authors are thankful to SAIF and IIT Madras for the characterization studies. 


\section{References}

[1] D. Xu, M. Jiang, and Z. Tan, "A new phase matchable nonlinear optic crystal L-abginine phosphate monohydrate," Acta Chimica Sinica, vol. 41, no. 6, pp. 570-573, 1983.

[2] A. Parkin, I. D. H. Oswald, and S. Parsons, "Structures of piperazine, piperidine and morpholine," Acta Crystallographica $B$, vol. 60, no. 2, pp. 219-227, 2004.

[3] Z. Dega-Szafran, I. Gşzczyk, D. Maciejewska, M. Szafran, E. Tykarska, and I. Wawer, ${ }^{" 13}$ C CP MAS NMR, FTIR, Xray diffraction and PM3 studies of some $\mathrm{N}$-( $\omega$-carboxyalkyl) morpholine hydrohalides," Journal of Molecular Structure, vol. 560, no. 1-3, pp. 261-273, 2001.

[4] I. Majerz, E. Kwiatkowska, and A. Koll, "The influence of hydrogen bond formation and the proton transfer on the structure of complexes of phenols with N-methylmorpholine," Journal of Molecular Structure, vol. 831, no. 1-3, pp. 106-113, 2007.

[5] H. Ratajczak, J. Baran, J. Barycki et al., "New hydrogenbonded molecular crystals with nonlinear second-order optical properties," Journal of Molecular Structure, vol. 555, pp. 149-158, 2000.

[6] C. B. Aakeröy, P. B. Hitchcock, and K. R. Seddon, "Organic salts of L-tartaric acid: materials for second harmonic generation with a crystal structure governed by an anionic hydrogenbonded network," Journal of the Chemical Society, Chemical Communications, no. 7, pp. 553-555, 1992.

[7] M.-L. Liu, "Morpholin-4-ium hydrogen tartrate," Acta Crystallographica E, vol. 68, part 2, p. o289, 2012.

[8] R. Sankar, C. M. Raghavan, M. Balaji, R. M. Kumar, and R. Jayavel, "Synthesis and growth of triaquaglycinesulfatozinc(II), $\left[\mathrm{Zn}\left(\mathrm{SO}_{4}\right)\left(\mathrm{C}_{2} \mathrm{H}_{5} \mathrm{NO}_{2}\right)\left(\mathrm{H}_{2} \mathrm{O}\right)_{3}\right]$, a new semiorganic nonlinear optical crystal," Crystal Growth and Design, vol. 7, no. 2, pp. 348353, 2007.

[9] A. Ashour, N. El-Kadry, and S. A. Mahmoud, "On the electrical and optical properties of CdS films thermally deposited by a modified source," Thin Solid Films, vol. 269, no. 1-2, pp. 117-120, 1995.

[10] J. M. Linet and S. J. Das, "Investigations on growth morphology, bulk growth and crystalline perfection of L-threonine, an organic nonlinear optical material," Physica B, vol. 405, no. 18, pp. 3955-3959, 2010.

[11] B. W. Mott, Microindentation Hardness Testing, Butterworths, London, UK, 1956.

[12] K. Sangwal, M. Hordyjewicz, and B. Surowska, "Microindentation hardness of $\mathrm{SrLaAlO}_{4}$ and $\mathrm{SrLaGaO}_{4}$ single crystals," Journal of Optoelectronics and Advanced Materials, vol. 4, no. 4, pp. 875-882, 2002.

[13] E. Meyer, "Untersuchungen über Härteprüfung und Härte," Zeitschrift des Vereins Deutscher Ingenieure, vol. 52, no. 17, pp. 645-654, 1908.

[14] E. M. Onitsch, "Systematic metallographic and mineralogic structures," Mikroskopie, vol. 5, no. 3-4, pp. 94-96, 1950.

[15] S. K. Kurtz and T. T. Perry, "A powder technique for the evaluation of nonlinear optical materials," Journal of Applied Physics, vol. 39, no. 8, pp. 3798-3813, 1968. 

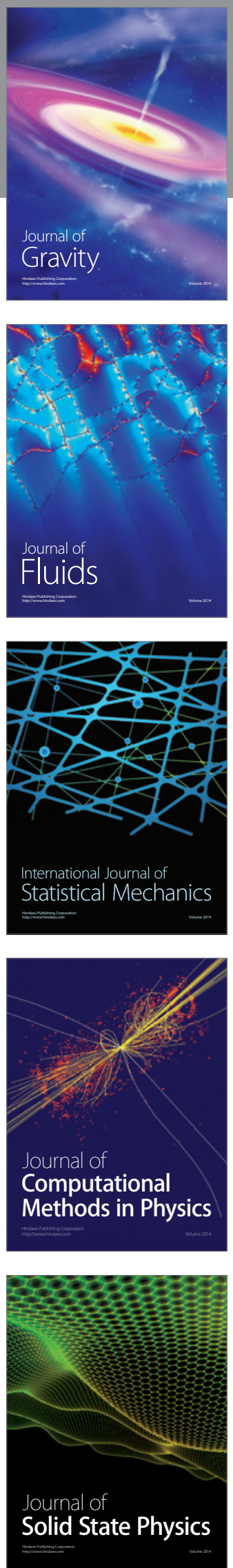

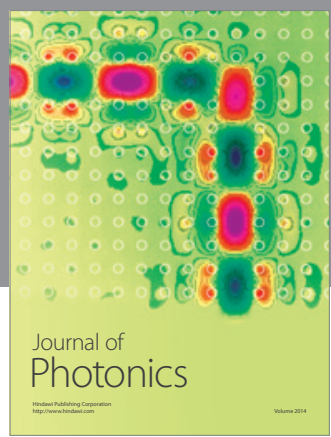

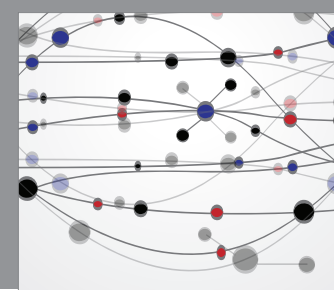

The Scientific World Journal

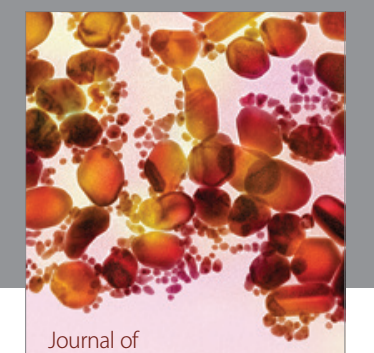

Soft Matter
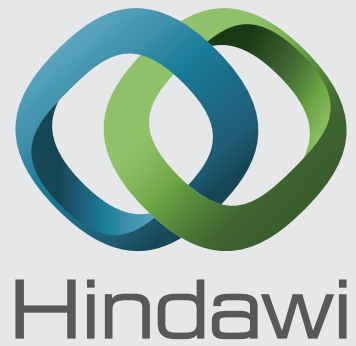

Submit your manuscripts at

http://www.hindawi.com
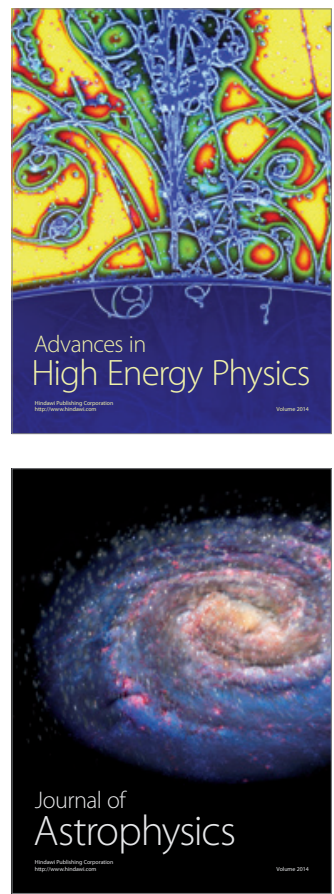
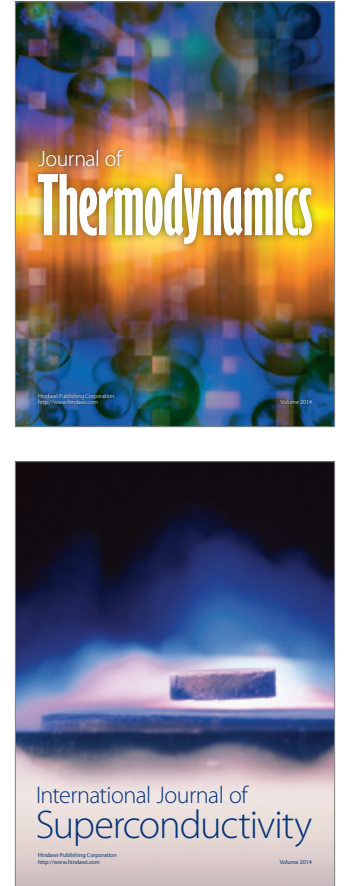
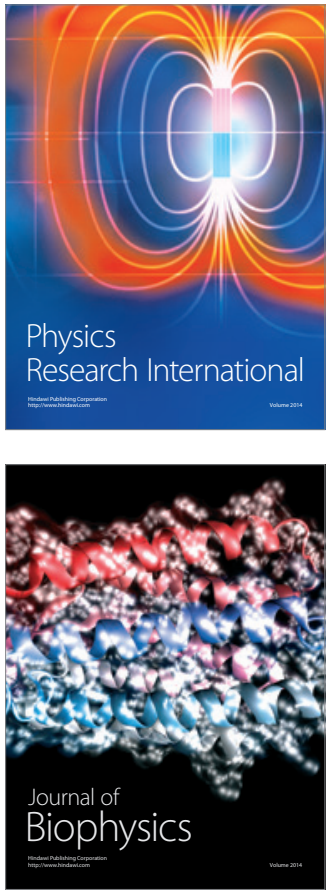
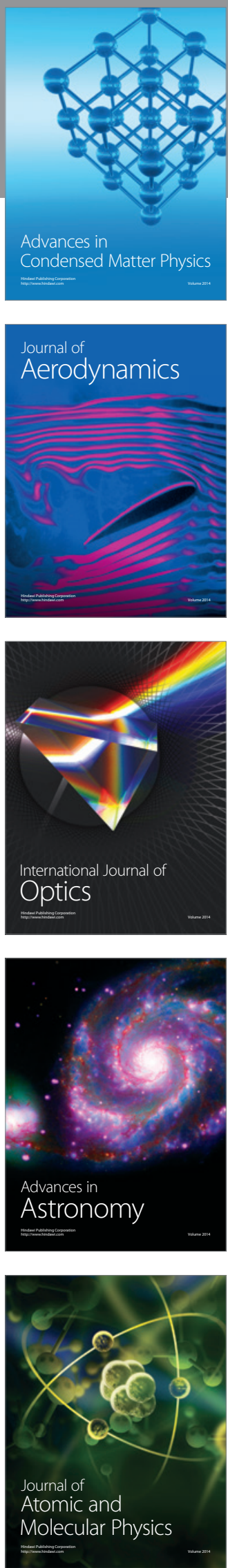